\title{
LOGISTICS STRATEGIES FOR RESOURCE SUPPLY CHAINS
}

\author{
Sebastian Trojahn \\ Otto-von-Guericke University Magdeburg \\ Magdeburg, 39106, Germany, Universitaetsplatz 2 \\ sebastian.trojahn@ovgu.de
}

\begin{abstract}
Resources play a decisive role in the functioning of our economy. Raw materials are used in the energy industry, the food industry and are the source for every good used and produced by humans. Efficient and reliable logistics chains are essential for the availability of these resources and goods.

Raw materials represent the beginning in each production chain, therefore the logistical optimization should find attention in the planning of these supply and demand chains. So far, however, logistics methods and strategies for raw materials have not been investigated. Instead, optimization of logistics chains is mostly implemented in the later production process.

This paper explains the reasons for the lack of application of logistics strategies in raw materials logistics, shows a portfolio of logistics strategies and assigns possible logistics strategies to selected raw materials. In addition to the definition of raw materials and resources from the point of view of production and logistics, this work provides a basis for logistics strategies for raw materials.
\end{abstract}

Keywords: logistics strategies, resource logistics, supply chain

\section{Motivation}

With the rapid rise of the world's population to approximately 7.5 billion people, which means a quadrupling of the total population within the last decade, the demand for resources increases continuously (Countrymeters, 2017)? There is no obvious end to the economic and production growth, because the resource-intensive way of life which is highly practiced by the industrial countries will eventually expand onto the emerging countries. In addition, the current state of recycling processes is inadequate to cover the growing need of resources. Therefore, it is necessary to guarantee the development of global trade is offset by a continuous optimization of production and logistics processes to ensure global supply. Within the resource logistics an important focus is on the provision of resources that need to be continuously optimized by processes in the field of transport, handling and storage.

But why are not every Supply Chains optimized? Why is the degree of optimization different? What is the reason for the (not-) application of logistic method?

In order to ensure a secure supply of resources, logistical methods and strategies throughout the different dimensions of the process must be continuously optimized or adapted. This paper presents possible strategies in the field of logistics and furthermore shows to what extent an application of these is useful, depending on the nature of the resources, and which may not have been used in the past.

\section{Logistic Methods}

\subsection{Supply Chain Management}

This process-oriented management approach serves to monitor all material, information and cash flows, taking into account all stakeholders. Colloquially speaking it is the management of modern supply chains, because Supply Chain Management (SCM) reflects the entire value creation process of an organization, the way from the supply source to the consumer. The approach of SCM is based on a simultaneous optimization of the effectiveness (Doing the right things) and the efficiency (Doing the things right) of a company as well as a harmonization of the four competitive factors. While the effectiveness is strategically oriented and largely based on external and long-term success, efficiency refers to the operational planning step and aims at ideal cost-benefit ratios. The four competition factors are time, cost, flexibility and quality to ensure customer satisfaction. The Figure 1 explains the competitive factors and their potential for optimization based on the strategic square in more detail 


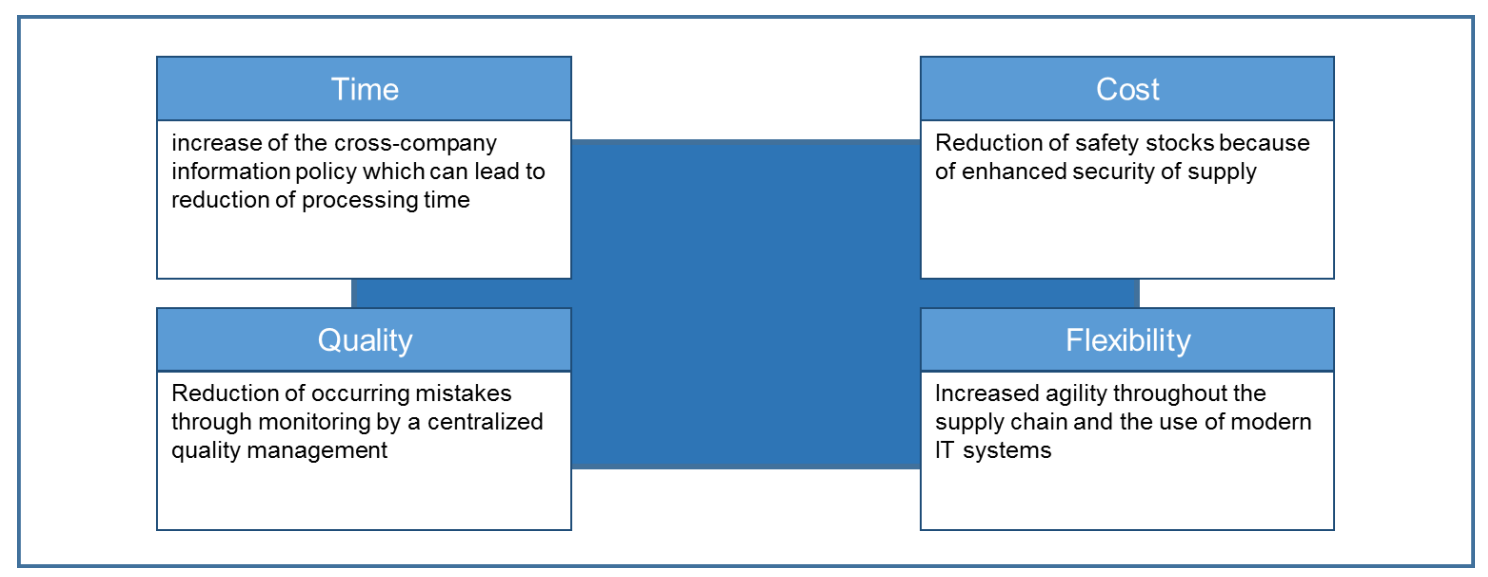

Figure 1. Strategic square of SCM

In general, the goal of SCM is to obtain high logistics performances with low logistics costs, low inventories and lead times through high flexibility. A multitude of challenges in the Supply Chain (SC) is based on the bullwhip effect (Guenther, 2005).

\subsection{Supply Chain Safety Management}

This concept is based on the SCM and focuses on increasing security of supply within a SC. This concept was created because of growing uncertainty, especially in the area of resource supply. Insufficient coverage of these can lead to significant economic damage within an SC because of the dependency between the companies involved. Safety can be interpreted in different ways. On the one hand, this can be designed as conscientious precaution to rule out any uncertainties within a network. Another aspect that includes the term security is the safety of persons and goods that are affected by unintentional influencing factors. This includes all factors that are outside the human factors, such as natural disasters. The last point that can hide behind the term security is the protection of the entire value chain against deliberately caused damage, such as theft, property damage or even terrorism.

The combination of the predictability of the risks and the optimal response to them is described by the Supply Chain Safety Management (SCSM) (Tandler, 2003).

\subsection{Sustainable Supply Chain Management}

Sustainable Supply Chain Management (SSCM) represents an alignment of a corporate concept, which is due to a sustained production and logistics.

For the purposes of the SSCM, the three dimensions of sustainability are incorporated into the structure of the original SC. These dimensions are the ecology, the economy and the social environment, which ensure sustainable development in the long term (Ganse, 2017). These three types of dimensions are defined in more detail in Figure 2 below.

The principle for a sustainable SC is: the stronger the collaborating companies within it work together, the more comprehensive and successful the SSCM can be implemented. An implementation of this complex process can be divided into four steps. First, an economic analysis is carried out, in which the current situation of a company is analyzed, and first proactive steps are taken. This is followed by the sustainability strategy, which deals with the assessment of potential opportunities and risks as well as a precise strategy that are to be implemented. This strategy leads to the next step, to derive measures from this and transform them into tangible work packages. These are then bundled for monitoring into appropriate counter indicators to measure progress within an SSCM. The final step, the reporting, deals with the evaluated key figures and possible measures to improve the system. This report makes it possible to draw a national and international comparison. (Morana, 2013) 


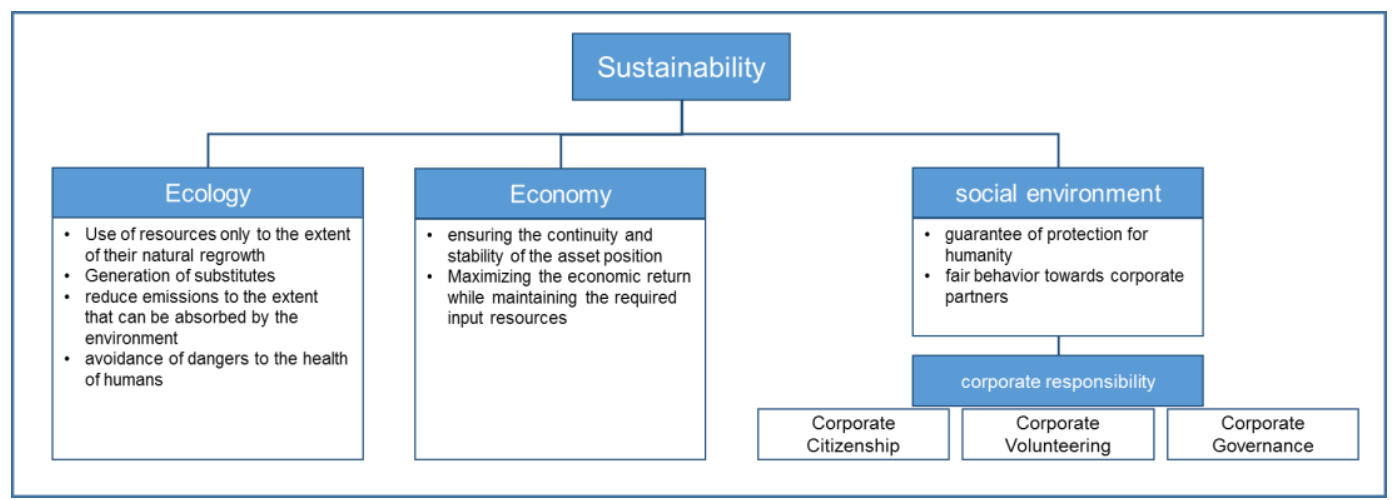

Figure 2. Dimensions of sustainability

Today, reporting is based on the Global Reporting Initiative (GRI) Standard 4.0. (GRI Empowering Sustainable Decisions, 2017).

The concept of SSCM offers the possibility to uncover bottlenecks within a supply chain. Furthermore, awareness of the responsible use of resources is enhanced, so either substitutes or secondary resources are used.

\subsection{Lean management}

Lean management has its roots in the Toyota Production System, TPS for short, which has the idea of continuously improving the quality of processes and minimizing wastage of any kind. However, lean management focuses not only on the reduction of Muda, i.e. the waste alone, but the reduction of the three main pillars of the loss philosophy, the so-called 3M. The 3M consist of Mura (imbalance), Muri (overloading) and the waste itself, the Muda. However, the $3 \mathrm{M}$ are strongly related, the waste resulting from the overuse and these results from the imbalance (Liker, 2014).

The term imbalance means losses that result from the lack of capacity adjustment in the context of production control. Overuse represents both human overload and miss planned asset utilization. However, the biggest source of loss is waste, which in turn is subdivided into seven types of wastes. The following figure shows these types of wastages.

For a clearer presentation, target categories and their meaning are briefly summarized below.

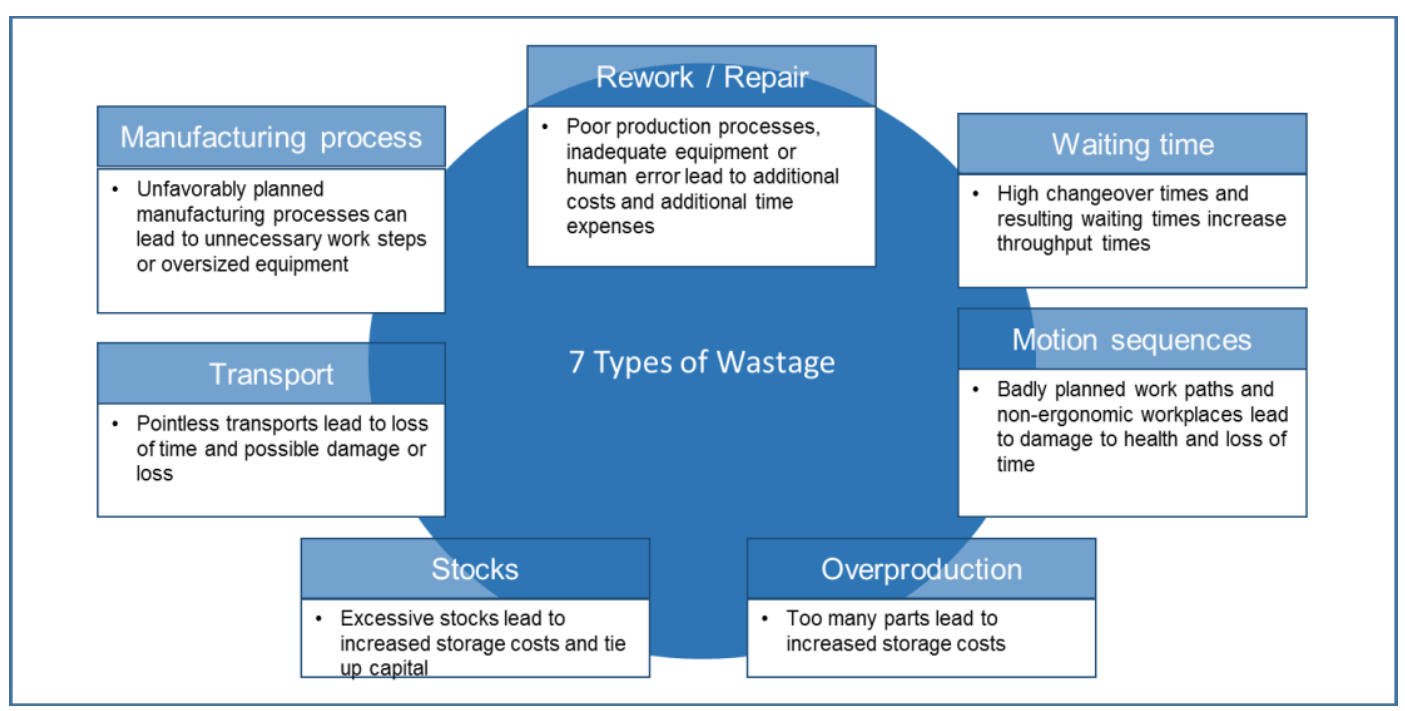

Figure 3. Types of wastage (Liker, 2014)

For a clearer presentation, target categories and their meaning are briefly summarized below.

Quality Best quality through continuous improvement

Time delivery on demand

Space Saving space 


$\begin{array}{ll}\text { Cost } & \text { economy } \\ \text { 3M } & \text { Avoiding waste } \\ \text { Create Value } & \text { Create Value Stream } \\ \text { Work } & \text { Group work in focus } \\ \text { Culture } & \text { Human being in focus }\end{array}$

\subsection{Leagile supply chain management}

Supply chains can be arranged with their interests. If there is a tendency for physical efficiency, this is called lean supply chain management. The base for this is to apply the principles of lean management to the SCM and thus deliberately avoid wastage. This concept was created because of companies that refuse radical restructuring in terms of corporate culture. Lean SCM draws on the mechanisms of a lean material flow through a purely methodical application. If, on the other hand, interests tend to be flexible, it means Agile Supply Chain Management. In this case, the focus of this network is on the quick response to difficult to assess or unpredictable demand situations. Basically, production steps in this system are triggered with the customer order.

When these two methods are combined, this is called Leagile Supply Chain Management. This tries to combine the waste approach and the flexibility. Two forms can be distinguished, one intermediate forms and the other hybrid forms. In the intermediate forms, the forms of lean and agile are linked together. In this form one assumes that one proceeds consistently from average expressions. The danger of these hybrid forms is that there are no clear goals. The last form, the hybrid form, is structured in a sleek and agile design. However, instead of being lean and agile, the alignments may have others and still fall under the hybrid forms. Another orientation can also be, for example, on the quality or sustainability aspect.

The basic principle of continuous improvement of the Lean approach and the flexibility approach are well compatible. Even if attention must be paid in Agile SCs to fluctuations in demand and thus the buffer volume is greater pronounced than in a pure lean management, this is not too much to each other in contradiction. (Hofmann, 2016)

To complete this chapter, the networks discussed above are shown in Figure 4 according to their characteristics listed in terms of their flexibility and in terms of non-waste.

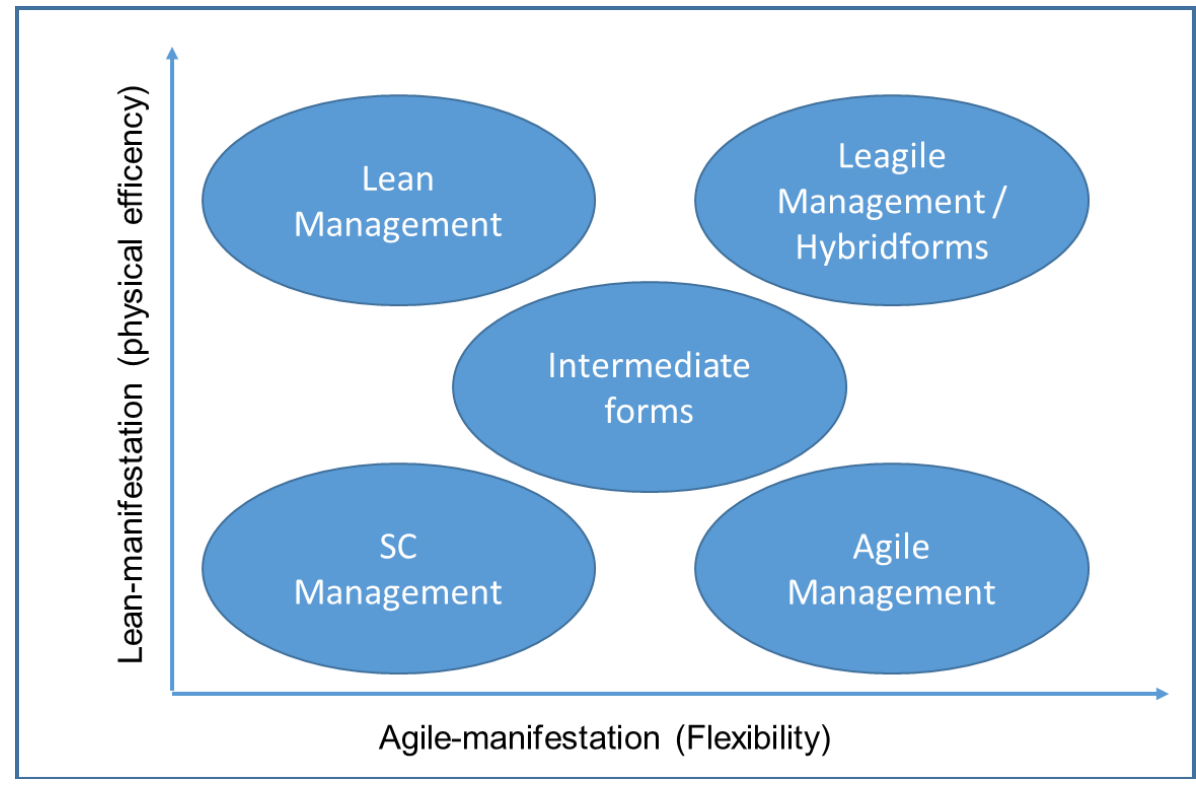

Figure 4. Types of networks

\section{Logistics Chains of Resources}

\subsection{Logistics chain: charcoal}

The process steps for processing charcoal are shown below. This process sequence may differ slightly throughout the individual mining areas. The general structure is shown in Figure 5. First, the 
delivery takes place, which can be either over or underground. The mined coal is usually transported via conveyor belts to the processing site. There it is purified, for instance soil debris. Afterwards the transport takes place for recycling. Here, a distinction is made between national and international recycling.

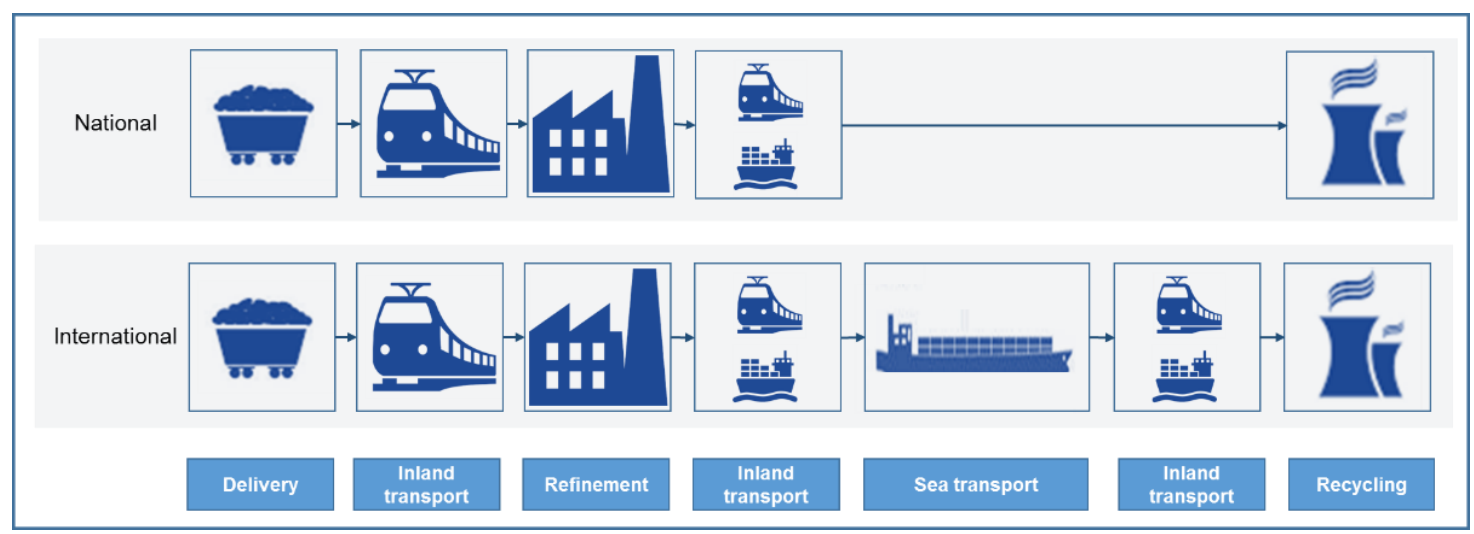

Figure 5. Value chain charcoal (Lambertz, 2012)

The characteristics of charcoal can be summarized as following:

\begin{tabular}{|c|c|c|c|c|c|}
\hline Coal & \multicolumn{5}{|c|}{ Characteristic } \\
\hline Capital commitment costs & Very low & low & medium & high & Very high \\
\hline Sales volume per year & Very low & low & medium & high & Very high \\
\hline Fluctuations in demand & Very low & low & medium & high & Very high \\
\hline Storability & Very low & low & medium & high & Very high \\
\hline Flexibility of resource flow & Very low & low & medium & high & Very high \\
\hline Delivery reliability & Very low & low & medium & high & Very high \\
\hline
\end{tabular}

Figure 6. Characteristics of charcoal

\subsection{Logistics Chain: Aluminium}

As was the case for the resource coal, the individual process steps for aluminium are also considered in more detail. Figure 7 splits the sequences into primary and secondary aluminium, reflecting the life cycle of aluminium products.

The first illustrated stream, which is considered in more detail, is that of the primary aluminium. First, the delivery and the transport take place for refining. Here, the recovered ore is freed of impurities. The now purified bauxite is then traded worldwide. For this purpose, it is transported to the next refining step, wherein each of the previously presented means of transport can be used. Following this refining step, the processed goods are transported to the nearest port by truck or freight train and shipped worldwide from there. (Knierzinger, 2017) From the port of arrival the bauxite is transported to the next refining stage. In this step alumina, also called clay, is produced from the bauxite using the Bayer process. To get one ton of primary aluminium, you need about four to five tons of bauxite or two tons of clay (Kammer, 2011). Therefore, it is cheaper to transport alumina in terms of transport costs, since much smaller amounts are needed. The aluminium now obtained can now be brought into various forms, such as ingots, sheets or strips. These are then further processed through further production steps in order to ultimately be formed into the final product. These production steps can once again extend around the globe, whereby all transport options can be used. 


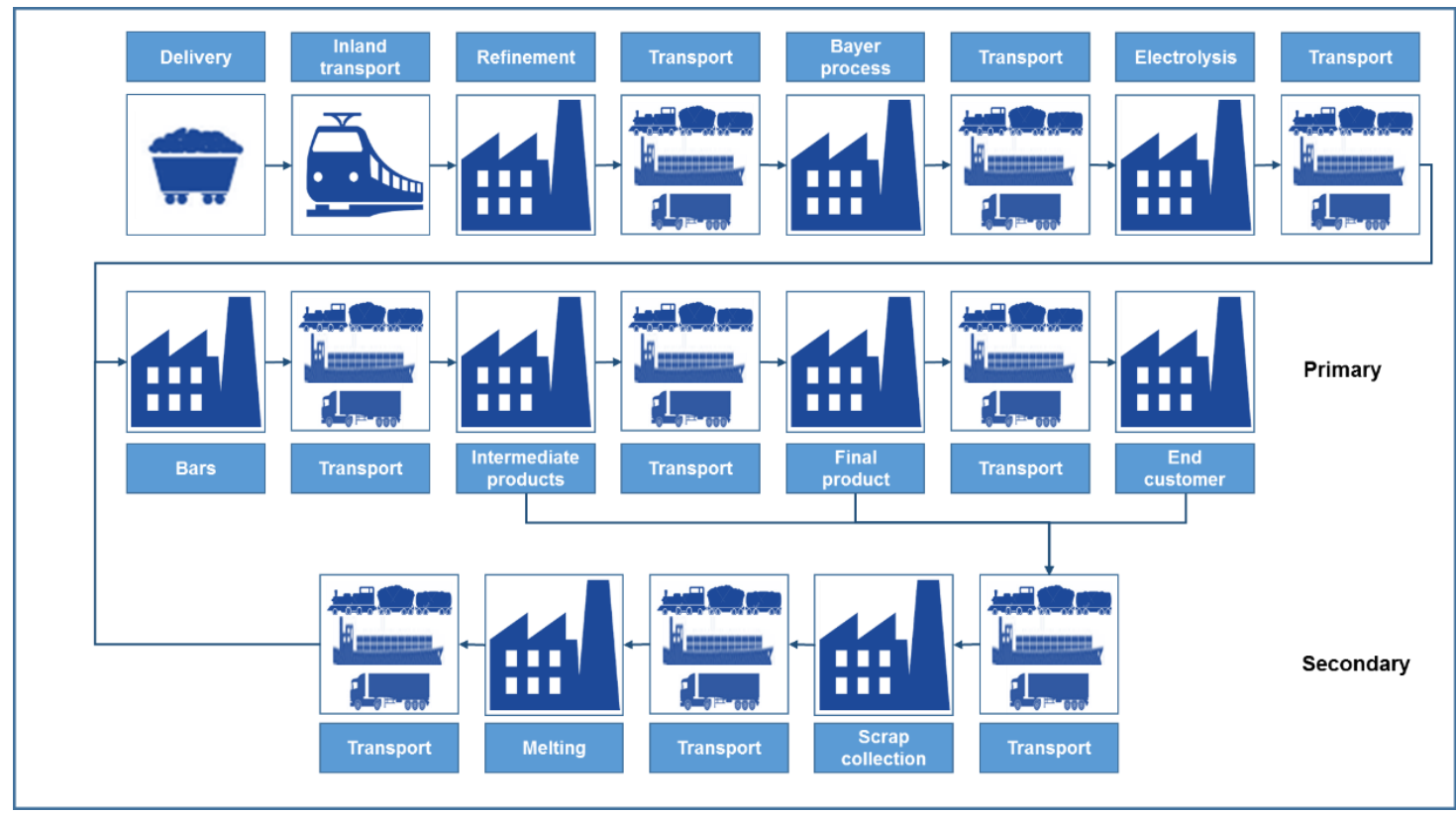

Figure 7. Value chain aluminium

The next illustrated stream deals with the secondary aluminium. However, the different types of scrap must first be differentiated here, the new scrap and the old scrap. New scrap means scraps which accrue in the individual production steps. On the opposite, there are the old scraps, which are already used aluminium. These disposed products are collected by metal dealers and classified into 22 different groups according to classification. The collected aluminium is then sold to the secondary aluminium sell points, where it is re-melted and returned to the aluminium loop (Ostermann, 2014). The characteristics of logistically relevant properties of aluminium are shown in the following figure.

\begin{tabular}{|c|c|c|c|c|c|}
\hline Aluminium & \multicolumn{5}{|c|}{ Characteristic } \\
\hline Capital commitment costs & Very low & low & medium & high & Very high \\
\hline Sales volume per year & Very low & low & medium & high & Very high \\
\hline Fluctuations in demand & Very low & low & medium & high & Very high \\
\hline Storability & Very low & low & medium & high & Very high \\
\hline Flexibility of resource flow & Very low & low & medium & high & Very high \\
\hline Delivery reliability & Very low & low & medium & high & Very high \\
\hline
\end{tabular}

Figure 8. Characteristics of aluminium

\subsection{Logistics Chain: rare soils}

At the beginning of the extraction process, the mining of the respective mineral layer takes place. As an example, in the Bayan Obo Mine in the north of China, this is done in the open pit. With the help of rope excavators, these layers are removed and reduced in size. The material is then transported to Baotou, which is $180 \mathrm{~km}$ away, by rail. There, the processing takes place including the oxide production. These oxides are then further transported for the production of metals, either domestically or abroad. (Ruettinger, 2017)

The extracted minerals from Australian mines are shipped to Malaysia where they undergo the next processing steps. In the following illustration, the individual steps of the value chain are shown graphically. Within the example of the production of a neodymium magnet the first three steps are included, recovery and concentration, separation into oxides, and refining of the oxides into metals, 
predominantly in China. Afterwards, the metals are further processed in alloys. This processing is done in Japan to a quarterly extent. Part of the production takes place in Europe, but the vast majority is done in China and Japan. (Schueler, 2011)

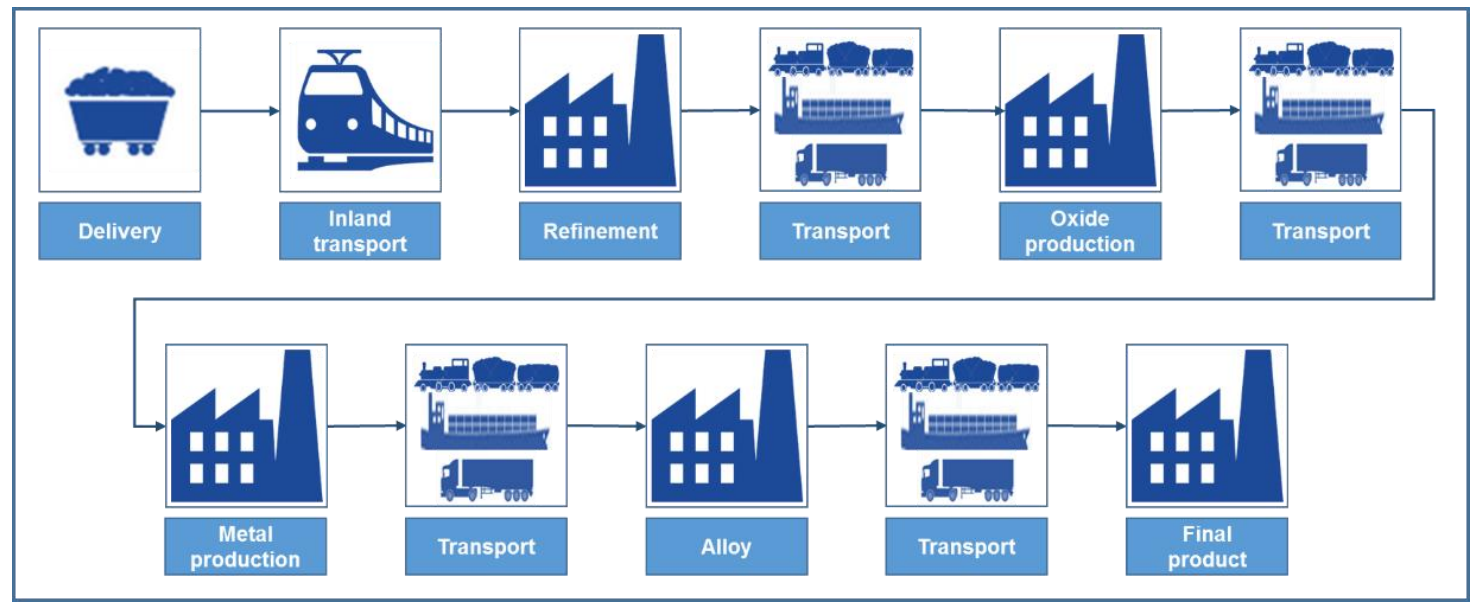

Figure 9. Value chain rare soils

\begin{tabular}{|c|c|c|c|c|c|}
\hline Rare Soils & \multicolumn{5}{|c|}{ Characteristic } \\
\hline Capital commitment costs & Very low & Low & medium & high & Very high \\
\hline Sales volume per year & Very low & Low & medium & high & Very high \\
\hline Fluctuations in demand & Very low & Low & medium & high & Very high \\
\hline Storability & Very low & Low & medium & high & Very high \\
\hline Flexibility of resource flow & Very low & Low & medium & high & Very high \\
\hline Delivery reliability & Very low & Low & medium & high & Very high \\
\hline
\end{tabular}

Figure 10. Characteristics of rare soils

Due to the dominance of China most of the steps in their own country take place. Only the final steps to the final product are made outside of China. By developing new mines, one can again see an increase in processing in other countries

\section{Decision Making for Logistics Strategies and Methods for Resources}

Each of the resources considered is initially assessed in terms of its characteristics in the logisticsrelevant properties, which are included in the decision-making process of the method selection. First, availability (geographic distribution) is used as a characteristic for the selection. Following this step, the willingness to cooperate for the resource will be examined, in addition the recyclability and the procurement model. In the case of the resources under consideration, it must be taken into account that much is procured from the international market. Thus, long delivery routes, by sea, rail or road, are necessary to calculate. It is therefore understandable that lean concepts are not applied for strategic / political commodities. In addition, it sometimes does not make sense to reduce inventory levels within the logistics chains if the buffers act as a speculative buffer or speculation object. The beginning of production chains implies for resources that the first step in the production chain is examined and there are no or barely any procurement costs / opportunity costs. The decision-making model for selecting logistics strategies is shown in the following figure. 


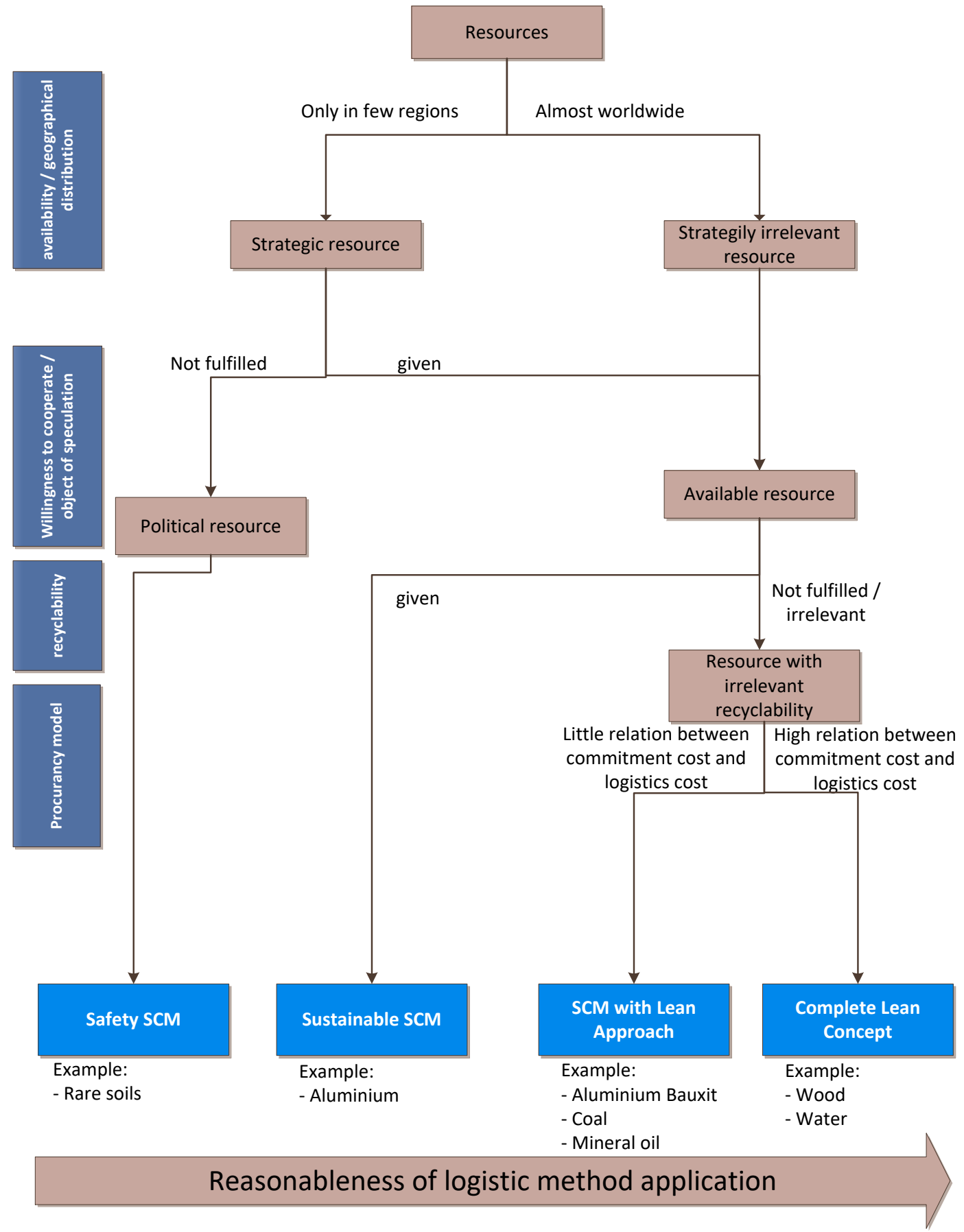

Figure 10. Reasonableness of logistic method application

\section{Conclusions}

It was demonstrated why sometimes no logistical optimizations within logistics chains are recognizable and meaningful.

However, it was clarified that companies be encouraged to conduct regular methods and analyses to ensure the continuous optimization of its own process. Value-added processes within the resource logistics are constantly changing.

The bulk goods were covered by the resource coal. This made clear that pure SCM should be used for these goods. Coal is still the most important material in the means of energy production today. However, in Germany, there is a trend that the coal market will decline. This trend is caused by the growing market of renewable energy sources. This is also due to the fact that the population is developing 
a steadily growing environmental awareness. Although the resource aluminium, which reflects the highdegradation products, is also distinguished by the fact that aluminium is designed very strongly for sustainability and is assigned an important role in the recycling process. The aluminium industry will continue to grow to use this resource in many technological areas. In addition, emerging economies are adapting to a resource-intensive lifestyle and the general world population is rising. The refining material with a lower amount of digests was represented in this work by the rare soils. This resource will play an increasingly important role in the future. But because of the price, it makes sense to pay greater attention to waste and to avoid any wastage.

This work provides an overview of all the important methods as well as example paths about the important dimensions that a company has to consider in terms of raw material logistics.

\section{References}

1. Countrymeters (2018) Weltbevoelkerung. - http://countrymeters.info/de/World

2. Ganse, F.W. (2017) Nachhaltigkeit_im_Supply_Chain_Management IHK 24. https://www.pfalz.ihk24.de/blob/luihk24/international/downloads/1274660/a39a4f60cd8ea9d1276ca 991e17c7a0c/Nachhaltigkeit_im_Supply_Chain_Management-data.pdf

3. GRI Empowering Sustainable Decisions (2017) Green Responsibility. - http://www.greenresponsibility.de/global-reporting-initiative-gri-veroffentlicht-g4-richtlinien-auf-deutsch/

4. Guenther, W.A. (2005) Wissenschaft in der Logistik - 14. Deutscher Materialfluss-Kongress "Intralogistik - Innovation und Praxis“. Duesseldorf: VDI Verlag.

5. Hofmann, E.K.O. (2016) Leagile Supply Chains: Zwischen Flexibilitaet und Kosteneffizienz. Logistik \& Foerdertechnik, pages 42-43.

6. Kammer, C. (2011) Aluminium Taschenbuch 1 Grundlagen und Werkstoffe. Berlin: Beuth Verlag $\mathrm{GmbH}$.

7. Knierzinger, J. (2017) Verein für Geschichte und Sozialkunde. http://vgs.univie.ac.at/_TCgi_Images/vgs/20160407084823_HSK35_Knierzinger.pdf

8. Lambertz, J.H.-W.S. (2012) Carbon Footprints fossiler Energietraeger in der Stromerzeugung. Energiewirtschaftliche Tagesfragen, (62), page 58.

9. Liker, J.K. (2014) Der Toyota Weg: Erfolgsfaktor Qualitätsmanagement - 14 Managementprinzipien des weltweiten erfolgreichsten Automobilkonzerns. München: FBV.

10. Morana, J. (2013) Sustainable Supply Chain Management. London - Hoboken: John Wiley \& Sons, Inc.

11. Ostermann, F. (2014) Anwendungstechnologie Aluminium. Berlin, Heidelberg: Springer Verlag.

12. Rüttinger, Lukas R.T. (2017) Umweltbundesamt. https://www.umweltbundesamt.de/sites/ default/files/medien/378/dokumente/umsoress_fallstudie_seltene_erden_china_bayan_obo.pdf

13. Schueler, Doris M.B. (2011) Final Report for the Greens/EFA Group in the European Parliament. Darmstadt: Oeko-Insitute.V.

14. Tandler, S.M. (2013) Supply Chain Safety Management - Konzeption und Gestaltungsempfehlungen. Wiesbaden: Springer Fachmedien.

15. Werner, H. (2017) Supply Chain Management - Grundlagen, Strategien, Instrumente und Controlling. Wiesbaden: Springer Gabler.

16. Zollondz, H.-D. (2013) Grundlagen Lean Management. Muenchen: Oldenbourg Wissenschaftsverlag. 